\title{
The Protection and Development of Hainan Province Wenchangpuqian Town Ancient Villages and Towns Under the Concept of the Grey Land
}

\author{
Zang Huiyi ${ }^{1,}$, , Shi Tingting ${ }^{2}$, Cang Yun ${ }^{3}$ \\ ${ }^{1}$ Department of City and Planning, Yancheng Teachers University, Yancheng, China \\ ${ }^{2}$ Personnel Agency of Science and Technology Department, Anhui jianzhu University, Anhui, China \\ ${ }^{3}$ Department of Architecture, Yancheng Architectural Design and Research Institute co. LTD, Yancheng, China
}

Email address:

zanghuiyide@163.com (Zang Huiyi)

${ }^{*}$ Corresponding author

\section{To cite this article:}

Zang Huiyi, Shi Tingting, Cang Yun. The Protection and Development of Hainan Province Wenchangpuqian Town Ancient Villages and Towns Under the Concept of the Grey Land. International Journal of Sustainable Development Research. Vol. 6, No. 1, 2020 , pp. 7-13. doi: $10.11648 /$ j.ijsdr.20200601.12

Received: November 3, 2019; Accepted: December 2, 2019; Published: April 23, 2020

\begin{abstract}
Ancient towns and villages are an important cultural heritage of the Chinese nation. With the acceleration of urbanization, many ancient towns and villages have been blindly developed and destroyed without proper protection planning, leading to the increasingly prominent contradiction between protection and development of ancient towns and villages. Using the concept of "grey land" as reference, this paper explores the multiple planning of ancient villages and towns and the small-scale progressive protection, development and utilization in the process of new urbanization. Taking puqian town, wenchang city, hainan province as an example, this paper deeply analyzes the status quo of puqian town and makes a phased plan for it. On the basis of the initial planning meeting the needs of the current situation, the follow-up planning leaves room for transformation and renewal, so as to construct a new round of protection measures and planning methods for puqian town. Through multiple rounds of protection guidance planning, puqian town has improved its functions, business forms and space environment, and put forward the strategy of progressive space protection and development of ancient villages and towns, injecting new impetus into the protection and development of ancient villages and towns, and promoting the protection and sustainable development of ancient villages and towns.
\end{abstract}

Keywords: Gray Land, The Ancient Villages and Towns, Protection and Development Utilization, Planning for Many Times, Flexible Control

\section{Introduction}

The ancient Chinese society was a rural society. Under the guidance of natural economy, people lived a life of resettlement in antu. Until 1949, when the People's Republic of China was founded, China's urbanization rate was just over $10 \%$. As Fei xiaotong said, "from the grass-roots level, Chinese society is rural". As a miniature of the "rural civilization", ancient villages and towns can reflect the unique features of various historical periods and serve as an important spiritual destination for people.

In the following decades, with the continuous development of urbanization, many ancient villages and towns were blindly developed and destroyed without proper protection planning. Shop in hainan wenchang, the former town protection and development and utilization planning, draw lessons from the suzhou industrial park zoning, the concept of "gray land" and the idea of flexible control, on the basis of in-depth analysis of the present situation of the ancient villages and towns of the ancient town planning by stages, in meet the demand of present situation on the basis of the initial planning for subsequent planning leave room for modification and update, so as to construct a new round of ancient villages and towns protection and planning method. 


\section{Introduction of the Concept of "Grey Land"}

\subsection{The Concept of "Grey Land" Was Proposed}

In 2007, the central planning institute first proposed the concept of "grey land", which refers to a kind of flexible land that has been repeatedly planned. External conditions are not mature, the future development of uncertain, land nature cannot be determined, land endowed with easy replacement function first, after waiting for external conditions are ripe, then convert them to other land for nature [1]. Ancient villages and towns protection and development in the process of using, and using the concept of "gray land", by planning and decision making in stages, with small microcirculation of conservation and renewal of the ancient town, to the culture of the ancient villages and towns and maximize economic benefits. The latter stage is to constantly supplement, guide and improve the former stage, which can avoid the waste of resources and the constructive destruction caused by blind development.

\subsection{Multiple Planning and Phased Decision-making}

A complete "grey land" planning requires multiple stages of planning to adapt the nature and function of land use to the renewal of urban development [2]. As a precious cultural heritage formed through thousands of years of history, ancient villages and towns need to sort out the historical context of ancient villages and towns, analyze the current situation, and formulate a comprehensive protection plan. This includes the planning of road network, land use, environmental improvement, and the delineation of core protection areas, providing necessary basic conditions for the development of ancient villages and towns. Along with the advancement of ancient town protection and development, can again or repeatedly replacement land properties and functions, guide the planning and implementation plan, gradually perfect the land use structure, promote the development of relevant industries.

\subsection{Sense of Advance, Small Update}

The core idea of "grey land" planning is actually a "leading" idea in the planning process [3]. That is, in the early planning, not only the current nature of land use and building functions are considered, but also certain space is reserved for the subsequent planning to cope with the future socio-economic and cultural development. Based on the concept of "gray land" under the protection and development of ancient villages and towns that can through its advanced ideas, in order to update planning by stages, small-scale, security design and construction to do fine, keep more historical information, the formation of short construction cycle, fund-raising easier and implementation results significantly [4].

\subsection{Elastic Control and Microcirculation Development}

The concept of "grey land" was finally implemented in the planning and implementation of ancient villages and towns, mainly including flexible control and micro-cycle development [5].

By dividing small plots, the control is carried out, and each plot is given certain indicators, so that the protection and renewal of the plot are carried out in small plots, so as to avoid the abnormal texture of ancient villages and towns. At the same time, it is flexible, transitional and operable enough to promote the diversified development of land and functions of ancient villages and towns. Small plots are easy to realize microcirculation development, especially those with complex land use conditions, from part to whole, from architectural monomer to architectural complex, from simple functions to complementary functions. Developing progressive microcirculation, and can keep rural harmonious and unified whole, to ensure that each phase of planning the optimal step by step, so as to make the ancient villages and towns can survive in the development of maximum flexibility and room for development.

Table 1. Comparison between "grey land" concept and "general way".

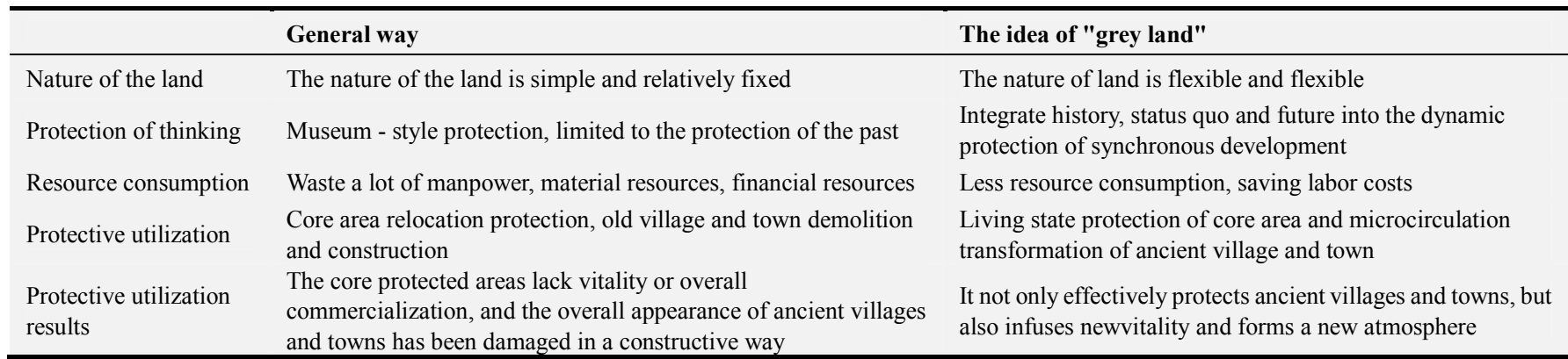

From the above analysis, it can be concluded that the protection and development of ancient villages and towns with conventional planning methods are more risky, and the museum-style protection also affects the long-term development of ancient villages and towns. And based on the concept of "grey land planning, can enhance the adaptability of ancient villages and towns to the outside world, to avoid the unnecessary consumption of resources, maintaining the original characteristics and injected new momentum, the ancient towns and villages can make full use of progressive elastic land space and function, benign development. 


\section{Planning and Application of the Concept of "Grey Land" in Puqian Town, Hainan Province}

\subsection{Current Situation of Puqian Town}

Puqian town, located in the northwest of wenchang city, hainan province, was once the land of immigrants from hainan island in the song dynasty. Since the establishment of the port in the Ming dynasty, it has been a famous port in the north of qiongdao and an important trading town, and has become an important export place for overseas Chinese in hainan. In 2008, the town was listed as one of the fourth batch of state-level historic and cultural towns. It has rich cultural heritage, such as the historic old street, the danjia fishing songs spread from generation to generation, and the mysterious undersea villages under the port of puqian on the west.

With the acceleration of urbanization, puqian town is faced with a series of problems that need to be solved urgently. The traffic order is chaotic, the road system is single, the t-junction is numerous, the disorder parking phenomenon is serious; New buildings fail to coordinate with traditional buildings. The ecological environment is deteriorating. In addition, because of the excessive development of tourism resources in recent years, ancient building protection work is ignored, causing the town to varying degrees of damage to the buildings and surrounding environment, the destructive development activities have caused many historical value of ancient building gradually disappear. Although the government has taken measures to deal with this phenomenon, it has not fundamentally changed the status quo. In addition, a series of crude and shoddy archaized buildings have appeared, which has damaged the historical environment of ancient villages and towns.

To solve above problems, the shop before the town of hainan province in the process of reform and development of the introduction of "gray land" concept, and applied to the recent three gradual transformation plan, guide before the shop in the town of protection and development further.

\subsection{The First Planning -- Protection Planning and Legal Protection}

Planning for the first time in front of the shop in-depth analysis, town land use present situation and distribution on the basis of cultural heritage, protection planning, protection strategy, from protection planning of ancient town protection and development and utilization of the bottom line, with advanced consciousness for late planning for reconstruction and development space, protective use provide legal guarantee for the future. This plan needs to retain enough flexibility to provide sufficient growth space for the subsequent planning [6].

The main contents of the first planning include the following aspects:

1) Target positioning of puqian town -- promoting development in protection and protection in development; Maintain historical style and features, inheriting the historical context, improve the living environment, create a cultural atmosphere, immerse spread before the town at sea port of atmosphere, be impressive scenery, unique distinctive characteristics of historical and cultural town.

2) Protection planning at the overall level -- strengthening the harmony and unity of the "sea, harbor and city" of puqian town in spatial form; To plan the land use in the town area, to comb the traffic network, to improve the supporting facilities, to improve the landscape environment, to protect the pattern of the old town, and to put forward the overall protection strategy.

3) Protection planning of key areas -- delineating core protection areas and construction control areas, and formulating corresponding protection measures, development intensity and construction control requirements (such as height control) [7]; When building a new building, it should fit the land function and architectural style of the surrounding area, and adapt to the urban development [8].

As shown in figure 1, in the first stage on the basis of recent research, before the shop in the town of regional present situation, the analysis of the defects in the current pattern of ancient town, formulate laws and regulations and so on, by restricting the indiscriminate down the building, the phenomena of through institutional safeguard, can better protect the core area of town before the shop, avoid the loss of regional architectural culture characteristics.

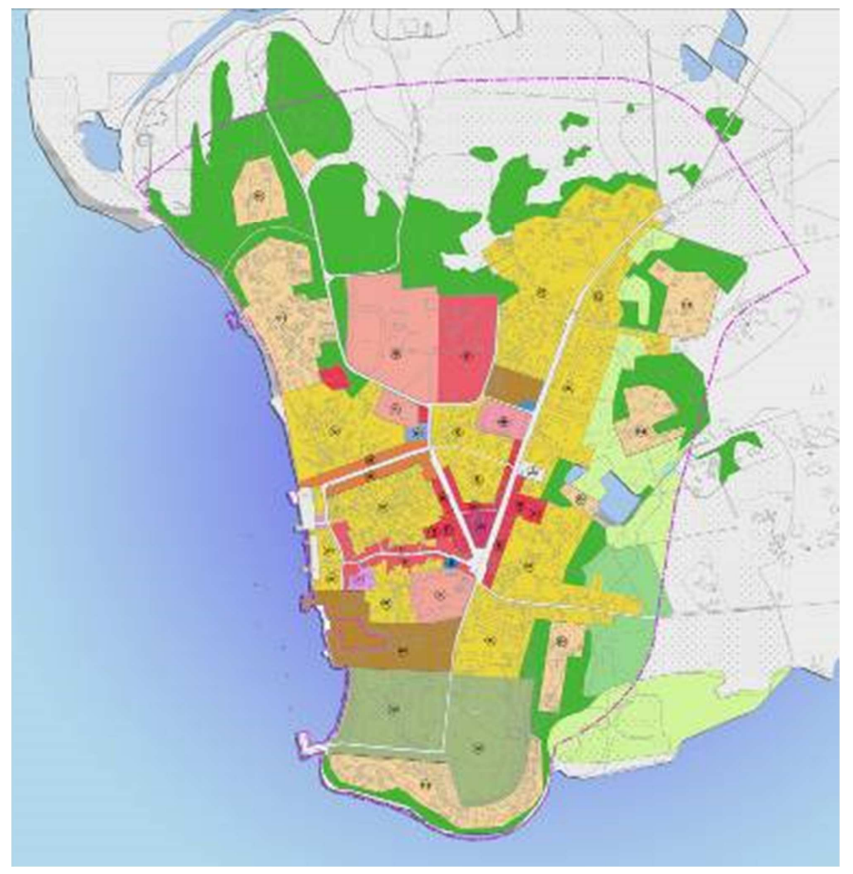

(a) Land usestatus of pre-shoptown. 


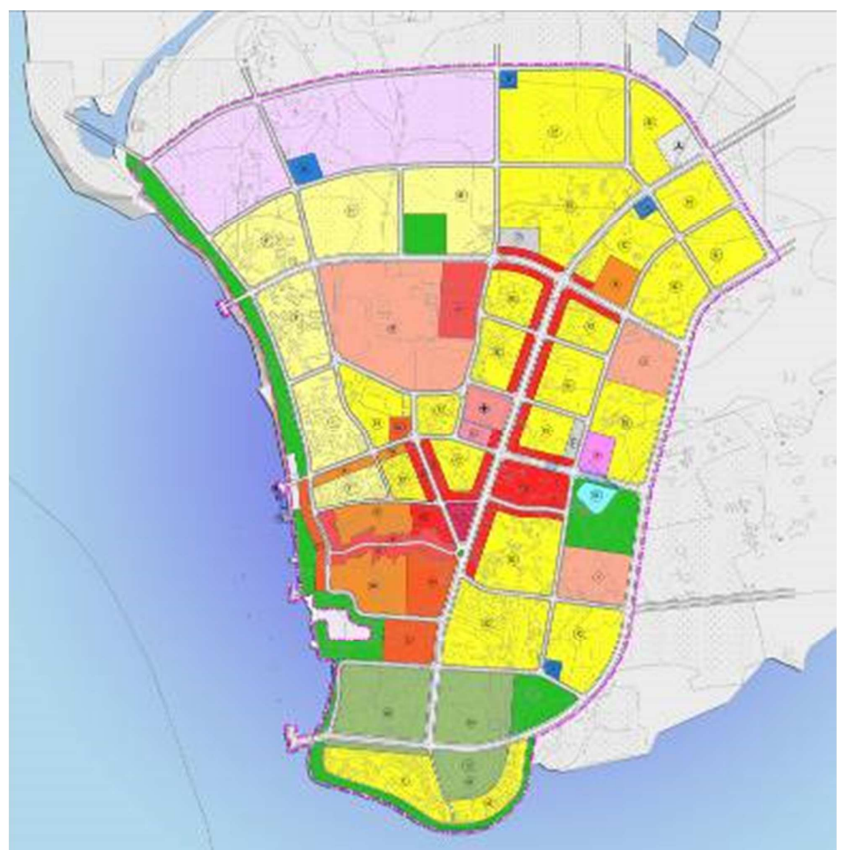

(b) Land useplanning of pre-shoptown.

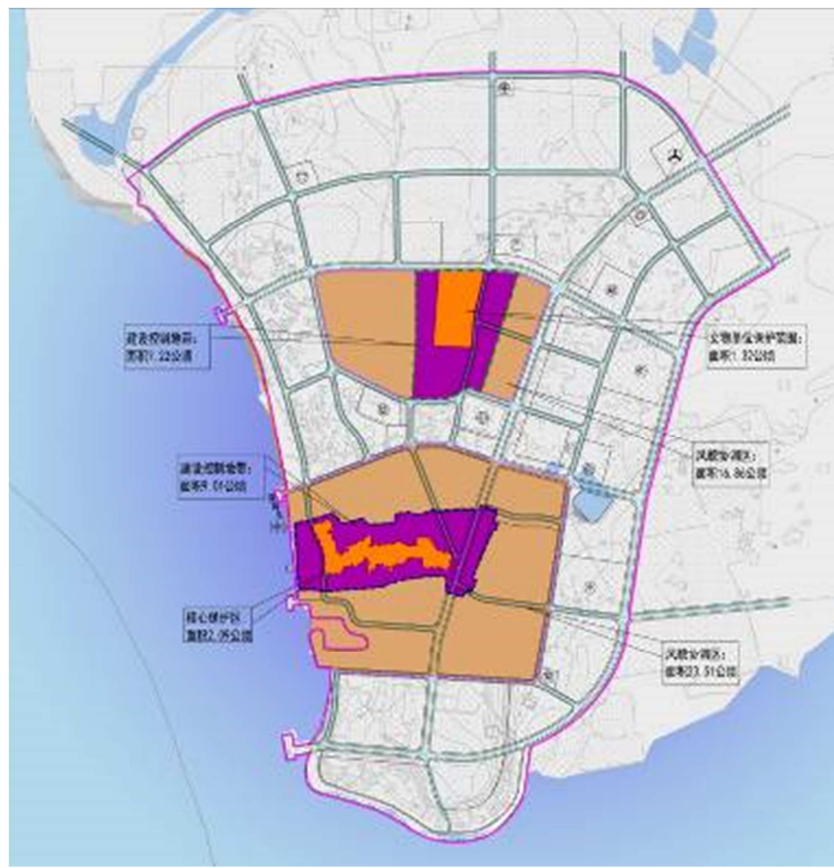

(c) Protectionscope of puqian town.

Figure 1. Peacher of puqian town.

\subsection{The Second Planning -- Guide Planning and Provide Space Strategy}

After the completion of the protection plan, it is clear that the core area should be protected and managed by the government. The construction control areas around the core area shall be planned and renovated with the developer as the main body, while other areas shall build and renovate themselves according to the principle of harmony of features and features. Before making legal implementation planning, usually to guide the planning, namely on the premise of the planning implementation main body, on the basis of planning for the first time, the core of ancient villages and towns and the surrounding area of space and the guide of planning.

The main contents of the second plan include the following aspects:

1) The space shape design based on the present situation texture -- based on the spatial and temporal sequence of development, the land value of puqian town was evaluated, and then a progressive renewal strategy was proposed. The architecture texture was analyzed, and the spatial morphological method was used to design the core area based on the general plane [8].

2) The core area of puqian town is planned for functional guidance --clear blocks around the town land property, update the building function, improve the efficiency of land use, improve core industry characteristics and cultural advantages;

3) Building space renovation planning -- buildings with large areas of damage and potential safety hazards should be reasonably dismantled, and buildings with poor quality and uncoordinated development should be reconstructed and rebuilt [9].

As shown in figure 2, texture after boot space become more abundant, in a program to determine the land use function under the premise of quadratic programming will be the old cannot be renovated to dismantle the overhang, become the new public corridor, runs through the town, and makes the spatial pattern of more flexible.

As shown in figure 3, while protecting traditional features, functional plates are gradually restored to improve the overall function of puqian town. In order to continue the traditional texture and maintain the integrity of traditional features, we should explore the tradition and implant new functions. To cope with the demand of modern life, build dominated by culture form business, blends together the traditional commercial, leisure, entertainment, artists working space, hotel, public activities and other functions in a body's comprehensive town.

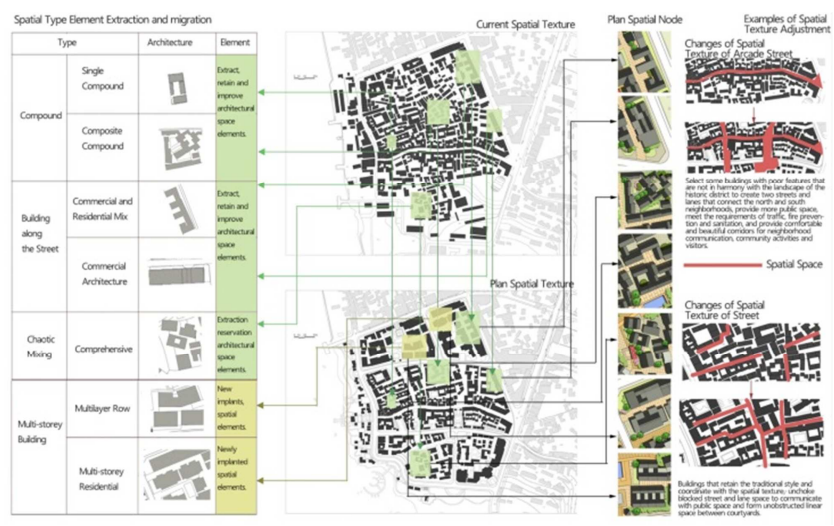

Figure 2. The schematic diagram of spatial texture adjustment for the second guidance planning. 


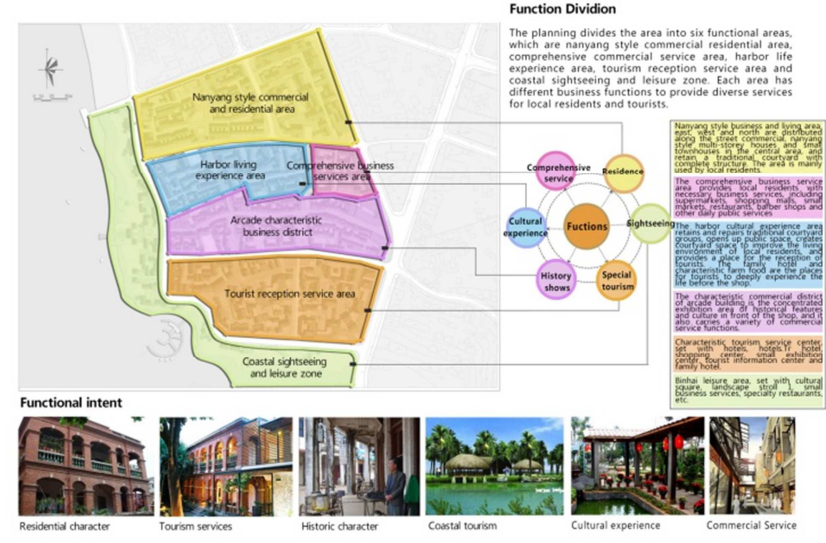

Figure 3. Function plate guide planning map.

\subsection{The Third Plan -- Implement the Plan and Improve the Functional Format}

The protection plan lacks the concrete measures to implement the plan, and the space guidance plan has no legal effect. According to the new social and economic development needs and the concept of "grey land", the third planning -- implementation planning -- was carried out for ancient villages and towns. The road network and the nature of land use in the core area of ancient village and town are planned in detail, the functions of each building are reasonably updated and developed, and the distribution of functional business forms is improved.

The main contents of the third plan include the following aspects:

1) Implement the guideline plan -- implementation guideline according to the scope of protection of the protection planning of the core space detail design guide planning, develop the protection plan implement guideline, divided into the ancient town protection and development of small plot control unit, and make each block protection and renovation strategy [10]; In terms of infrastructure, we should make the best use of high-value infrastructure in the first planning to avoid unnecessary waste and realize the circular development of economy and economy.

2) Detailed planning of land use functions -- after the first protection plan defines the main body of development, the nature of land shall be replaced according to the function project setting of the second guided planning [11]; In order to maintain the vitality and flexibility of the land in ancient towns, the land compatibility of the new planned land is clarified by taking into account geographical location, land use situation, building type, economy and culture and other factors.

3) Small scale protection and renewal -- according to land adjustment, functional renewal of some plots and transformation and renewal of some plots; Set up shop front town to protect the special management, operation organization, control the complex external environment, carry on the organic renewal of the cycle gradually [12]. As shown in figure 4 shows, through the flexible control of carding and gradual planning, make the shop before the town land functions more perfect, skin texture is richer, satisfy the needs of current development, and leaves room for future development.

In addition, the concept of "gray land" in construction application in: first, building some transitional function, when most of the buildings with the transition conditions, then according to the nature of land and buildings characteristics change functions, such as phasing out big density, layer number is high, the old buildings, a new multifunctional buildings. In this way, on the one hand, high value buildings are guaranteed to be used continuously; on the other hand, the waste of buildings is avoided and development costs are reduced.

In addition, the concept of "gray land" in construction application in: first, building some transitional function, when most of the buildings with the transition conditions, then according to the nature of land and buildings characteristics change functions, such as phasing out big density, layer number is high, the old buildings, a new multifunctional buildings. In this way, on the one hand, high value buildings are guaranteed to be used continuously; on the other hand, the waste of buildings is avoided and development costs are reduced.

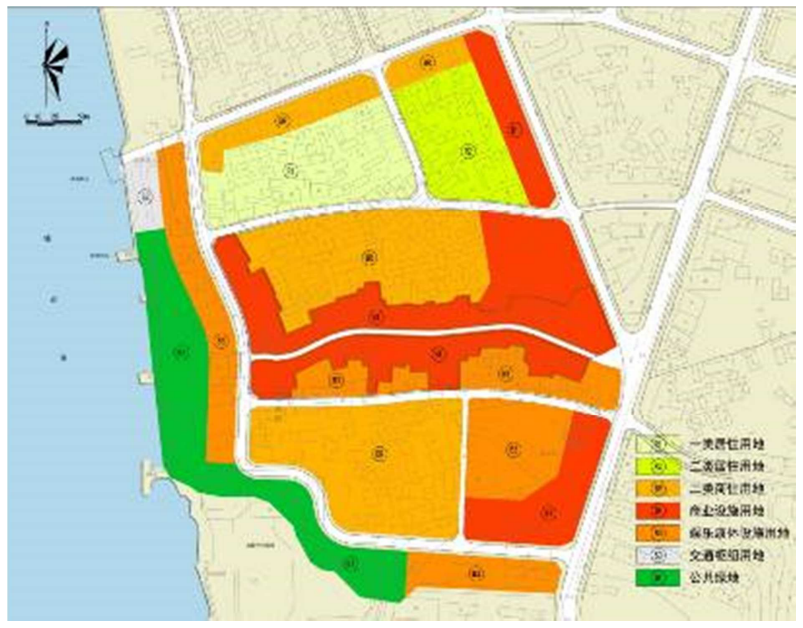

(a) First plansite plan.

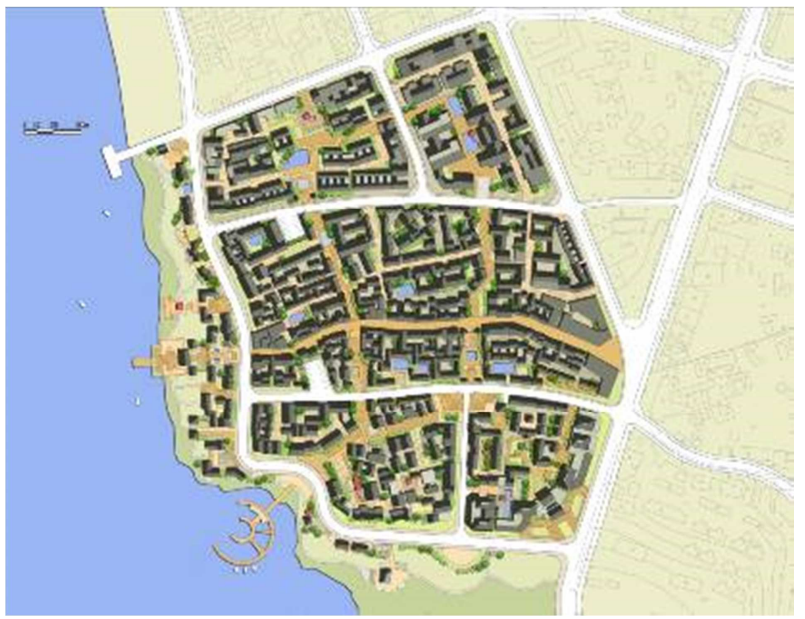

(b) The second plangeneral guide chart. 


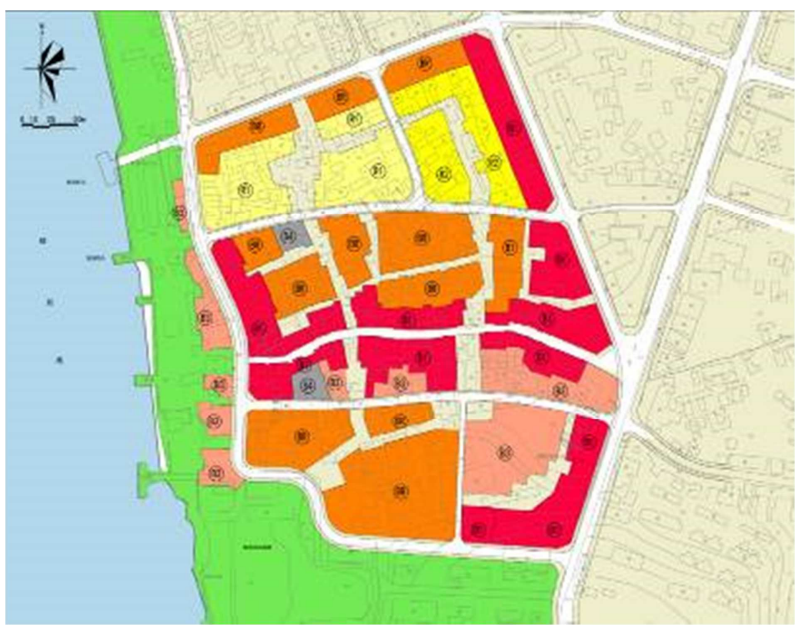

(c) The third planland plan.

Figure 4. Puqian town three times land use plan.

\section{Prospect of the Future Development of Ancient Villages and Towns Under the Concept of "Grey Land"}

\subsection{Integration of Land Resources of Ancient Villages and Towns}

Land resource is non-renewable, so reasonable replacement is very important to land use properties and functions, this is we need to control the population growth of the ancient villages and towns, ensure the healthy, sustained and coordinated development. The concept of "gray land" is standing in the long run, considering from the use of land and space resources, infrastructure, constantly update and transformation of ancient villages and towns embodies the sustainable development of land use dynamics [13]. To promote the intensive use of land resources can not only generate enormous economic benefits at the current stage, but also bring considerable potential value to every stage of the follow-up planning.

\subsection{Protect the Features of Ancient Villages and Towns}

The historical style and features of the ancient villages and towns represented mainly by the ancient buildings and its surrounding environment [14], it also bears the local charming scenery and the humanistic spirit, to moderate the development of tourism, therefore, cannot be absorbed into immediate economic benefits regardless of the natural and humanistic environment protection.

The protection and renewal of buildings in different stages under the concept of "grey land" are mainly reflected in the following aspects: on the overall level, attention is paid to the protection of the surrounding environment of ancient buildings, and core protection areas are delimited; At the guiding level, it analyzes the features of the landscape and features, and then renovates, repairs and updates the buildings inheriting the texture of ancient villages and towns. At the implementation level, protect the update unit division, phases of construction, protection and renovation in determining the ancient villages and towns construction framework under the premise of overall protection, fixed function building should keep for a long time, and implementation of protection and reconstruction method and appropriate adjust the architectural functions, such as high recovery value of building function and adjusted to better people spiritual and cultural needs of the ideal function, including the public space of the square, commercial, catering, leisure, entertainment, and other functions [15]. The potential land use value of ancient villages and towns has been gradually developed by gradually implementing the strategies of improving streets, maintaining buildings and beautifying the environment.

\subsection{Supporting and Updating the Infrastructure of Ancient Villages and Towns}

According to the statistical results of a large number of questionnaires, residents are not satisfied with the infrastructure of ancient towns and villages. The road system in most ancient towns and villages is single, with chaotic traffic order and serious parking disorder. Therefore, the road system needs to be re-planned and comprehensively renovated. In addition, the aging power supply facilities and drainage systems need to be inspected and updated to create a good living and living environment for residents and provide quality services. Ancient villages and towns should focus on upgrading transportation, power supply and drainage facilities, establishing an effective garbage recovery system, and collecting and harmless disposal of household garbage.

\subsection{Protect and Develop the Ecological Environment of Ancient Villages and Towns}

Pay attention to the protection of the ecological environment and development, ancient villages and towns first, rational utilization of natural resources to prohibit the phenomenon of deforestation, protect the natural landscape of ancient villages and towns and animal and plant diversity, protect the ecological balance development; Secondly, we should reduce the environmental burden brought by tourism on ancient villages and towns, improve the quality and consciousness of tourists, cherish the ancient cultural relics and buildings, and cherish the ancient villages and towns. Using microbial technology to centrally, sewage and waste harmless handling, actively promote the environmental protection consciousness of the residents, reduce the damage to the ecological environment, realize the economy development of ancient towns and villages in harmony with the ecological environment protection.

\subsection{Protect the Development Model Step by Step}

The cultural heritage of ancient villages and towns is relatively rich, and large-scale renewal may cause constructive damage to ancient villages and towns. The advanced and dynamic nature of the concept of "grey land" can better deal with the contradiction between protection and 
development. Before stage planning, perfect infrastructure, as far as possible reserves the use value of high buildings, the moderate protective renovation, the nature of land and buildings and update of ancient villages and towns function, which can avoid a lot of destructive dismantling and redundant construction, enables the ancient villages and towns to continuous upgrading, gradual development.

\section{Conclusion}

Based on the concept of "gray land", this paper carries out multiple planning for puqian town, and provides spatial strategies through guiding planning through protection. Through the implementation of planning, improve the functional format. The original style and historical features of the town have been maintained, while new elements have been added. In the process of new urbanization, the land space environment of ancient towns and villages should be protected, the life of ancient towns and villages should be continued, and the protection and sustainable development of ancient towns and villages should be promoted through multiple planning and small-scale gradual protection and development planning. It provides a planning method for building the image of the ancient village, which contains both historical and cultural accumulation and full of modern flavor.

\section{Acknowledgements}

Project source: general project of philosophy and social sciences research in universities of jiangsu province (2019SJA1726).

Project approval number: 2019SJA1726.

\section{References}

[1] Zhang Qian, Yang Zhongwei, Research on grey land [N], Suzhou institute of technology, 2009, 22 (02), 42-55.

[2] Yang Zhongwei, Zang Huiyi, Planning and exploration of grey land in suzhou industrial park [J], Regulatory division, 2009, $16(8), 21-24$.

[3] Shen Liping, Zhang Kai, New appearance of the ancient city -planning of neighborhood 1 and 2 of suzhou ancient city $[\mathrm{J}]$, Urban and rural planning, 2007 (7), 126-130.
[4] Zhou Siying, Yang Zhongwei, The reference significance of the"grey land" theory to the protection and renewal of historical blocks in old cities [J], Small-town construction, 2012 (5), 97-100.

[5] Liu Sifeng, Emergence and development of grey system theory $[\mathrm{J}]$, Journal of nanjing university of aeronautics and astronautics, 2004, 36 (2), 267-268.

[6] He Xinkai, Protection and development of historical blocks in urban renewal $[\mathrm{N}]$, Journal of hefei university of technology (social science edition), 2006, 20 (5), 186-188.

[7] Gu Jianming, Understanding of the protection of historical blocks in China [N], Journal of tongji university (social science edition)[N], 2001, 14 (3), 24-27.

[8] Liu wei, yu liyin, Reference significance of protection and redevelopment of foreign historical blocks [J], Anhui architecture, 2008, 15 (5), 7-9.

[9] M. Tim Tinker Kit M. Kovacs, Mike O. Hammill, The reproductive behavior andenergetics of male gray seals (Halichoerus grypus) breeding on a land-fast ice substrate, Behav Ecol Sociobiol, 1995 (36), 159-170.

[10] Andrew D. Basiago, The search for the sustainable city in 20th century urban planning, The Environmentalist, 1996 (16), 135-155.

[11] H. Akgun, Remediation of the geotechnical problems of the Hasankeyf historical area, southeastern Turkey, Environmental Geology, 2003 (44), 522-529.

[12] Yang Zhongwei, Yan Jing Wen, gray land" urban planning method research [J]. Urban development research, 2009 (8), 69-76.

[13] Wang Yu cun, Sunning, Yang zhongwei, Cleaning, moisturizing, moisturizing, the theory of grey land for industrial heritage protection and reuse of reference $[\mathrm{J}]$, Urban development research, 2011, 18 (12), 49-52.

[14] Liu xuefei, wang jianxin, Exploration on small-scale reconstruction model of urban historic blocks $[\mathrm{J}]$, Urban construction theory research (electronic edition), 2011, (13).

[15] Chen shanshan, The impact of multi-agent intervention on the vitality of historical blocks -- a case study of nanluoguxiang and yanzi xiejie historical blocks in Beijing [C], Proceedings of China urban planning annual conference 2007, 2007: 2040-2048. 